\title{
Temporal and spatial foraging patterns of three Asian honey bee species in Bangalore, India
}

\author{
Allison M. YounG ${ }^{1,2}$ (1) Patrick L. KoHL ${ }^{3,4}$ (1) Benjamin RutsChMANN ${ }^{3,4}$, \\ Ingolf StefFan-Dewenter ${ }^{4}$ (i), Axel Brockmann ${ }^{3}$ (D) Fred C. Dyer ${ }^{1,2}$ (1) \\ ${ }^{1}$ Department of Integrative Biology, Michigan State University, 288 Farm Lane, East Lansing, MI 48823, USA \\ ${ }^{2}$ Ecology, Evolution, and Behavior Program, Michigan State University, East Lansing, MI, USA \\ ${ }^{3}$ National Centre for Biological Sciences, Tata Institute of Fundamental Research, Bellary Road, Bangalore 560065, \\ India \\ ${ }^{4}$ Department of Animal Ecology and Tropical Biology, Biocenter, University of Würzburg, Am Hubland, 97074, \\ Würzburg, Germany
}

Received 17 June 2020 - Revised 9 November 2020 - Accepted 16 December 2020

\begin{abstract}
Honey bees (genus Apis) are important pollinators in Asian tropical agricultural and natural ecosystems, yet the Asian species remain vastly understudied compared to the European honey bee, Apis mellifera. We studied the temporal and spatial foraging patterns of three co-occurring Asian honey bee species in Bangalore, India, to gain a better understanding of how they coexist. We found evidence for temporal resource partitioning, with Apis cerana having activity peaks in the early mornings, Apis florea initiating foraging later in the day, and Apis dorsata having the potential to do much of its foraging activity at night, even when the moon is not yet up. Apart from the established species differences in foraging ranges, we found limited evidence of spatial partitioning of the landscape. Although individual colonies foraging in parallel often focused their foraging effort on different patches, all three species preferred foraging in cultivated garden areas to seminatural or urban areas. These observations add to the growing evidence for a key role of gardens as foraging habitat for bees in cities.
\end{abstract}

\section{Asian honey bees / spatio-temporal foraging / coexistence / resource partitioning / urban ecology}

\section{INTRODUCTION}

Bees, and in particular honey bees in the genus Apis, play a critical role in pollination in both agricultural and natural ecosystems (Corlett 2004; Potts et al. 2010; Hung et al. 2018; Requier et al. 2019). The role of bees as pollinators, in turn, depends on their foraging ecology, including foraging range, daily patterns of activity, and exploratory behavior. An understanding of

Corresponding author: A. Young,

younga46@msu.edu

Allison M. Young, Patrick L. Kohl and Benjamin

Rutschmann contributed equally to this work.

Manuscript editor: James Nieh bee foraging biology is especially important in tropical ecosystems (Bawa 1990; Corlett 2004; Donaldson-Matasci and Dornhaus 2012), where the vast majority of forest trees (Bawa 1990) and agricultural crops (Klein et al. 2007; Dainese et al. 2019) depend upon animal (primarily bee) pollinators and where ecosystems are currently under threat from human actions such as land use change, pesticide use, and pollution, as well as parasites and pathogens (Oldroyd and Nanork 2009; Potts et al. 2010; Brown et al. 2016; Thimmegowda et al. 2020).

A large amount of research conducted on tropical bees has been conducted in the New World tropics, which has a highly diverse bee fauna (Roubik 1990; Freitas et al. 2009). While attention 
has been paid to the tropical bee communities of Asia (Oldroyd and Wongsiri 2006; Koeniger et al. 2010; Hepburn and Radloff 2011), which differ markedly from those of the Neotropics, there is much that is still unknown. Pollination services in the Neotropics are provided by a large number of solitary bee species in addition to a diverse biota of highly social stingless bee species, whereas pollination by social bees in the Old World tropics is often dominated by honey bee species in the genus Apis, one species of which (Apis dorsata) can migrate seasonally and thus rapidly increase in number when resources become available in a given habitat (Roubik 1990; Dyer and Seeley 1994; Liow et al. 2001; Oldroyd and Wongsiri 2006; Stewart et al. 2018; Mukherjee et al. 2019). The diversity of solitary and stingless bee species is reduced in the Asian tropics (Michener 1979; Corlett 2004), possibly in part because of the competitive advantage honey bees possess through their powerful dance communication system and through the additional benefits that eusociality provides over solitary bees (Dyer 2002; Dornhaus et al. 2006; Kohl et al. 2020).

In spite of the importance of Asian honey bee species in Asian tropical ecosystems, their foraging ecology remains poorly studied as compared to the Western honey bee (Apis mellifera) (but see Dyer and Seeley 1991a, b; Batra 2003; Oldroyd and Wongsiri 2006; Hepburn and Radloff 2011; Kohl et al. 2020). To understand the role that Asian honey bee species play in Asian tropical forests, it is necessary to gain a greater understanding of the basic dynamics of foraging behavior in the different honey bee species, including how they interact with each other. Like A. mellifera, the Asian honey bee species are highly eusocial, have large colonies, are generalist flower visitors, and communicate food locations through the dance language (Lindauer 1971; Dyer and Seeley 1991a; Dyer 2002; Kohl et al. 2020). These traits ensure that colonies are highly effective and competitive at locating and exploiting ephemeral floral resources, an advantage in seasonal tropical forests (Dornhaus and Chittka 2004; Price and Grüter 2015). At the same time, these traits potentially result in high interspecific competition for food (Koeniger and Vorwohl 1979; He et al. 2013; Stewart et al. 2018), as anywhere from two to four honey bee species coexist in most parts of their native ranges (Ruttner 1988; Roubik 1990). In light of the potential for high competition that we expect to see in tropical forest ecosystems, an important open question is how these highly competitive honey bee species coexist? Answering this question requires basic information about spatial and temporal patterns of foraging activity and how foraging correlates with biological differences among the Asian honey bee species.

Previous research on Asian honey bees has identified several traits that may influence the way coexisting species partition resources according to spatial distribution, time of day, or accessibility of different floral resources. For example, there is a fivefold range in worker body mass from the dwarf honey bee Apis florea to the giant honey bee A. dorsata (Dyer and Seeley 1987; Underwood 1991). Body size differences may be associated with differences in tongue length (Waddington and Herbst 1987; Cariveau et al. 2016), foraging range (Greenleaf et al. 2007), sensory capabilities (Somanathan et al. 2009; Streinzer et al. 2013), and metabolic rate (Dyer and Seeley 1987). Differences in metabolic rate could influence differences in the profitability of specific resources (Schaffer et al. 1979; Willmer and Stone 2004) or the ambient temperature at which bees can fly (Dyer and Seeley 1987; Dyer and Seeley 1991b). Studies of the three sympatric species A. florea, Apis cerana, and A. dorsata in Sri Lanka, Thailand, and India indeed showed that they differ in foraging range (Punchihewa et al. 1985; Dyer and Seeley 1991a; Kohl et al. 2020). Interestingly, however, the observed differences did not correspond to the expected body size related pattern. Instead, the medium-sized species A. cerana consistently had the smallest foraging range, while the smallest species had an intermediate and the largest species had the largest foraging range. The deviation of $A$. cerana might be explained by selection pressures related to differences among honey bee species in nest architecture. The Eastern hive bee, A. cerana, resembles A. mellifera in nesting in cavities, while A. dorsata and A. florea nest in the open on a single comb that is enveloped by a protective curtain of bees (Oldroyd et al. 2008; Bhagavan 
et al. 2016). Open-nesting bees have far less comb area per worker and thus maintain less brood per worker than do cavity-nesting species (Seeley et al. 1982); this might lead to different resource needs and foraging decisions of colonies and individual workers, respectively (Dyer and Seeley 1991b). Finally, A. dorsata has a unique ability to forage on moonlit nights surrounding the full moon; this ability may provide an additional release from competition by enabling this species to forage when other honey bee competitors are unable to fly (Dyer 1985a).

The difficulty in assessing the importance of these various trait differences is the lack of reliable comparative information about the foraging behavior of the species in the same environment. Many previous studies have focused on the behavior of a single species at a time (e.g., Dyer 1985a, b; Batra 2003). Studies that have examined multiple species have revealed species differences in daytime activity (Dyer and Seeley 1991b; Oldroyd et al. 1992; Rinderer et al. 1996; Bakker 2001; Koeniger et al. 2010; Cui and Corlett 2016), but these studies are limited by their focus solely on bee abundances on flowers (Oldroyd et al. 1992; Rinderer et al. 1996; Koeniger et al. 2010; Cui and Corlett 2016) or their use of only one colony of each species (Dyer and Seeley 1991b), or by their examining foraging behavior without considering its relationship to the surrounding landscape (Punchihewa et al. 1985; Dyer and Seeley 1991a; but see Bakker 2001). Critically, no comparative study of Asian honey bee foraging activity to date has included information on the nocturnal activity of A. dorsata.

In this study, we compared the foraging behavior of three sympatric Asian honey bee species, A. florea, A. cerana, and A. dorsata, living in the same environment at the same time. We tracked colony patterns of foraging activity to determine if species are active at different times of day, including nocturnal observations for A. dorsata. We also used waggle dance recordings (from Kohl et al. 2020) to map the foraging locations indicated by dancing bees and to compare each species' spatial resource exploitation. Our study adds to an understanding of the similarities and differences in the spatio-temporal foraging activity of these species, as it includes both diurnal and nocturnal observations of daily foraging activity and includes data for multiple colonies and days.

\section{METHODS}

\subsection{Study location and dates}

We studied three species of Asian honey bees, A. florea, A. dorsata, and A. cerana, in Bangalore, Karnataka, India, at the National Centre for Biological Sciences-Tata Institute of Fundamental Research (NCBS). We compared sets of colonies during three observation periods: February 2017, March 2017, and March to April 2018. NCBS is located in a primarily residential district in the northern part of the city of Bangalore, adjacent to the University for Agricultural Sciences, Gandhi Krishi Vignana Kendra Campus (GKVK). NCBS and GKVK are surrounded by extensive fields of agricultural vegetation in addition to the ornamental vegetation on the campuses and surrounding residential neighborhoods. Wild colonies of all three species are common throughout this habitat. The study colonies were all located on the NCBS and the GKVK campuses at the time of the study and were located within $800 \mathrm{~m}$ of each other.

The observation colonies used in this study-four colonies per species-were the same colonies as those used by Kohl et al. (2020), who give a detailed description of the colony preparation. In brief, we acquired A. cerana colonies (colonies $\mathrm{C} 1-\mathrm{C} 4$ ), which can be kept in manmade hive boxes, from local beekeepers and placed them into an observation hive containing 6 moveable frames (each $25 \times 19 \times 2 \mathrm{~cm}$ ), keeping the combs in their natural parallel arrangement. Colonies of A. florea, which nest on twigs in dense vegetation, were collected on the campuses and placed in well-shaded but uncovered observation boxes (colonies F1-F4). For A. dorsata, we studied naturally occurring colonies (colonies D1-D4) that had built their nest hanging from concrete overhangs on buildings on the NCBS and GKVK campuses. 


\subsection{Colony activity measurements}

To compare species differences in temporal colony foraging activity, we collected parallel foraging activity data for colonies of all three study species. In 2017, we recorded daytime foraging observations from 0700 hours to 1900 hours on February 18th (colonies C1, C2, F1, and F2) and on March 10th (colonies C3, F3, and D2). As sunrise occurred at 0640 hours and 0630 hours (all times Indian Standard Time), respectively, for those days, we likely missed some of the diurnal activity of these colonies. The sun set at 1826 hours and 1829 hours, respectively, so we did not miss diurnal observations in the evenings. In 2018, we observed one colony per species (C4, F4, and D3) for a continuous 50-h period from March 5th to 7th (covering two days and two nights), and for a continuous 36-h period from March 30th to 31st (covering two days and one night). On these days, we made regular observations from 0600 hours onwards until daytime foraging activity ended in A. cerana and A. florea (between 1900 hours and 2000 hours). During the following nights, we recorded A. dorsata's nocturnal activity (see below) and additionally visited the $A$. cerana and A. florea colonies at 2300 hours, 0230 hours, and 0530 hours to check whether these bees are actually strictly diurnal. Sunrise occurred at 0632 hours from March 5th to 7th and 0617 hours on March 30th to 31st, while sunset occurred between 1829 hours and 1832 hours, so we feel confident we did not miss any activity during these periods.

To compare foraging activity, we counted the number of arriving bees during hourly 6-min census periods; after calculating the average number of arrivals per minute, we then extrapolated those counts to give an estimated number of arrivals during the entire hour. For A. cerana and A. florea, we counted the number of bees entering the hive or landing on the top of the colony, respectively, during the census period. For A. dorsata, the colony's position on the building where the bees had built their comb made it difficult to view the colony directly. Therefore, we used a video camera attached to a rig on the roof above the ledge where the colony was located to record activity. Arrivals during each census period were counted from later observation of videos. Nocturnal activity of $A$. dorsata was recorded from sunset to sunrise using an infrared-sensitive video camera (Linnse Model LCAM-42). The field of view of the infrared camera was not large enough to take in the entire colony. Although we probably underestimated nocturnal foraging activity for this species, we estimate that we captured $90 \%$ of the nocturnal activity. During daylight hours, we used a Panasonic Model HC-X929 video camera that had a wider field of view, so we could have captured closer to $100 \%$ of diurnal activity.

\subsection{Forage mapping}

To compare the foraging ranges and the locations of the patches exploited by each study colony, we performed forage mapping (Visscher and Seeley 1982). To perform this technique, we measured the direction and distance signals in randomly selected dances indicating natural foraging locations recorded by Kohl et al. (2020) (in Kohl et al. only the distance information was analyzed; directional information was not considered and no foraging maps were created). We analyzed the dances of four colonies from each species over the course of our three observation periods (see Supplementary Table 1 for a breakdown of observations by colony and date). The dance analysis from video recordings was done using the software UTILIUS FAIRPLAY 5 (ccc software, Leipzig, Germany). To decode the distance information of the dances, the total duration of 2-24 (mean \pm s.d.: $7 \pm 3.02$ ) circuits per dance (where a "circuit" consists of the waggle run plus the return run to begin the next waggle run) was measured and then divided by the number of circuits recorded. Average circuit durations were then translated into foraging distances using species-specific distance-circuit duration calibration functions that had been empirically obtained in Bangalore using bees trained to feeders at a series of known distances (A. cerana: $y=$ $0.0069 x+1.3502 ;$ A. florea $: y=0.0055 x+$ 1.9701; A. dorsata: $y=0.006 x+1.2171$, with $y=$ circuit duration in seconds and $x=$ foraging distance in meters; Kohl et al. 2020). 
Both circuit duration and waggle run duration correlate highly with foraging distance (von Frisch 1967) and are regularly used to determine foraging distance (Visscher and Seeley 1982; Dyer and Seeley 1991a; Beekman and Ratnieks 2000; Couvillon et al. 2015). Waggle run duration is more accurate as it removes variation due to forager motivation (Seeley et al. 2000). However, in this study, we used circuit duration because the low quality of infrared video used for nocturnal dances prevented precise measurement of waggle run duration for $A$. dorsata's nocturnal dances. Circuit duration reduces this measurement error because we take the measure from the average of multiple consecutive dance circuits. (In addition, analyzing circuit duration is much more time efficient (Kohl et al. 2020).) Because we used circuit duration for the nocturnal dances, we did the same for the diurnal dances to allow for easier comparisons.

To determine the compass direction of the patch being signaled, we used the direction code of the dance elucidated by Karl von Frisch (1967) for A. mellifera and by Lindauer (1956) for the Asian species. In A. mellifera, $A$. cerana, and the diurnal dances of A. dorsata, the orientation of the waggle run relative to the upward direction on the dance surface correlates with the angle the bee had flown relative to the solar azimuth (we obtained the solar azimuth from the NOAA Solar Calculator for all dances). For the nocturnal dances of $A$. dorsata, it is unclear what compass reference bees use. Although illumination, assumedly provided by the moon, is required for flight, nocturnal dances are not referenced to the moon's azimuth (Dyer 1985a). Instead, they may be referenced to position of the sun at sunset or sunrise, although this is not known. Because of this uncertainty, we felt uncomfortable generating nocturnal forage maps for A. dorsata. In the case of A. florea, we estimated the compass direction being signaled directly from the alignment of the waggle run. This species does not use gravity as a reference for dancing, but instead dances on the horizontal and near horizontal upper portions of the comb, and directly "points" to the food source (Lindauer 1956; Dyer 1985b; Dyer 2002).

The combination of flight distance and flight direction gives an estimate of the radial coordinates (relative to colony location) of the foraging site signaled by a dancer. With respect to the geographic location of the respective honey bee colonies, we translated these radial coordinates into geographical coordinates, which we then used for the analysis of spatial habitat use.

\subsection{Habitat use analysis}

To determine whether the bees preferentially used certain habitat types, we quantified the expected and observed proportions of visited habitat types. We imported the colony locations into QGIS version 3.10 and overlaid them onto the Web-based Esri World Imagery layer (sources: Esri, DigitalGlobe, Earthstar Geographics, CNES/Airbus DS, GeoEye, USDA FSA, USGS, Aerogrid, IGN, IGP, and the GIS User Community). A land cover map was manually generated based on knowledge of the study area and visual inspections of satellite imagery. We chose four habitat categories to classify the landscape: "urban" (including impervious surfaces like buildings, construction sites and infrastructure), "garden," "seminatural" (including areas with tree cover and fallow fields), and "agricultural." We created a circular area around every colony location based on the respective species' 90th percentile of the foraging ranges obtained from the colonies used in this study (A. cerana: $274 \mathrm{~m}$, A. florea: $459 \mathrm{~m}$, A. dorsata: $730 \mathrm{~m}$; Kohl et al. 2020). We divided these areas into rectangular 10 $\mathrm{m} \times 10 \mathrm{~m}$ bins and intersected it with the land cover map to assign each bin to one of the four habitat use types (see Supplementary Figure 1). We calculated the relative proportion of each habitat type, which we considered the expected proportional habitat use, for all landscape sections surrounding the colony locations. To calculate the observed habitat use as indicated by waggle dance locations, we counted the number of dances in all bins for each colony, summed the number of dances for each habitat, and divided by the total number of dances from each colony within the 90th percentile range. We then compared the 
expected and observed habitat use to get the "deviation from expected habitat use."

\subsection{Data analysis}

We used descriptive statistics and data figures to present in detail our observations. We tested whether observed proportional habitat use differed from known habitat proportions using chisquare tests. All data figures were created using the package ggplot2 in R version 3.5.1 and foraging maps were created using QGIS version 3.10.

\section{RESULTS}

\subsection{Temporal patterns of foraging activity}

Our parallel activity measurements revealed clear species differences in the daily timing of foraging activity between A. cerana, A. florea, and $A$. dorsata (Figures 1, 2, 3, and 4). During daylight hours, A. dorsata and A. cerana had a much wider range of activity than did $A$. florea . Apis cerana foraged from sunrise to sunset and usually exhibited peak activity in the early mornings. For example, colonies $\mathrm{C} 1$ and $\mathrm{C} 2$ showed peak activity at 0900 and 0800 hours, respectively (Figure 1), though it is likely that we missed some of their earlier activity before our observations began at 0700 hours. The foraging activity pattern of $A$. dorsata generally resembled that of A. cerana during the day (Figures 3 and 4). In contrast, A. florea consistently began foraging later in the morning than A. cerana and A. dorsata, generally $2 \mathrm{~h}$ after sunrise, and typically showed peak activity in the early afternoon. For example, colonies F1 and F2, recorded at the same time as A. cerana colonies $\mathrm{C} 1$ and $\mathrm{C} 2$, did not even begin foraging until 0900 or 1000 hours, and their activity peaked at 1200 and 1400 hours respectively (Figure 1). In general, once they began foraging, A. florea 's foraging activity stayed high for the rest of the day, although they reduced foraging earlier in the evenings than either A. cerana or A. dorsata (Figures 1, 2, 3, and 4). This apparently divergent foraging schedule in A. florea was consistent between colonies and across observation years. Activity across species did not peak at similar times even when colonies were observed in the same location on the same day.

In addition to the different activity schedules during daylight hours, we found that a substantial fraction of $A$. dorsata's overall activity took place at night and that they were the only species to be active at night (Figures 3 and 4). We provide a more detailed analysis of $A$. dorsata's nocturnal behavior in Section 3.4.

\subsection{Spatial foraging patterns}

Going beyond Kohl et al. (2020), who presented an analysis of the species differences in foraging distance distributions in Bangalore, we compared in detail the spatial foraging pattern of each study colony and present actual forage maps for each of the three observation periods (Figures 5, 6, and 7). Colonies tended to focus their foraging efforts on specific patches, often leading to clustered, multimodal distance distributions where different colonies foraged at different patches. A clear example of this separation of coexisting colonies onto unique patches can be seen in Figure 5, where both observed A. cerana colonies foraged in garden areas on the NCBS campus but concentrated their efforts on patches in separate areas, either to the west $(\mathrm{C} 1)$ or the east $(\mathrm{C} 2)$. Similarly, the observed A. florea colony foraged outside of the NCBS campus even though their colony was located in the same area as the A. cerana colonies (Figure 5). Bimodal foraging distributions were commonly observed, as exhibited by A. cerana colony C3 (Figure 6) and A. dorsata colony D3 (Figure 7), and generally consisted of a peak close to the colony location in garden areas on campus and a peak further off campus in agricultural or urban areas.

\subsection{Habitat use}

Our forage maps show that in almost all studied colonies (except F1, which primarily foraged in seminatural areas, and D4, for which we could not collect dance direction data and therefore could not perform forage mapping), the majority of foraging effort seems to be focused on the garden areas located on the NCBS campus (Figures 5, 6, and 7). That said, individual colonies expended 

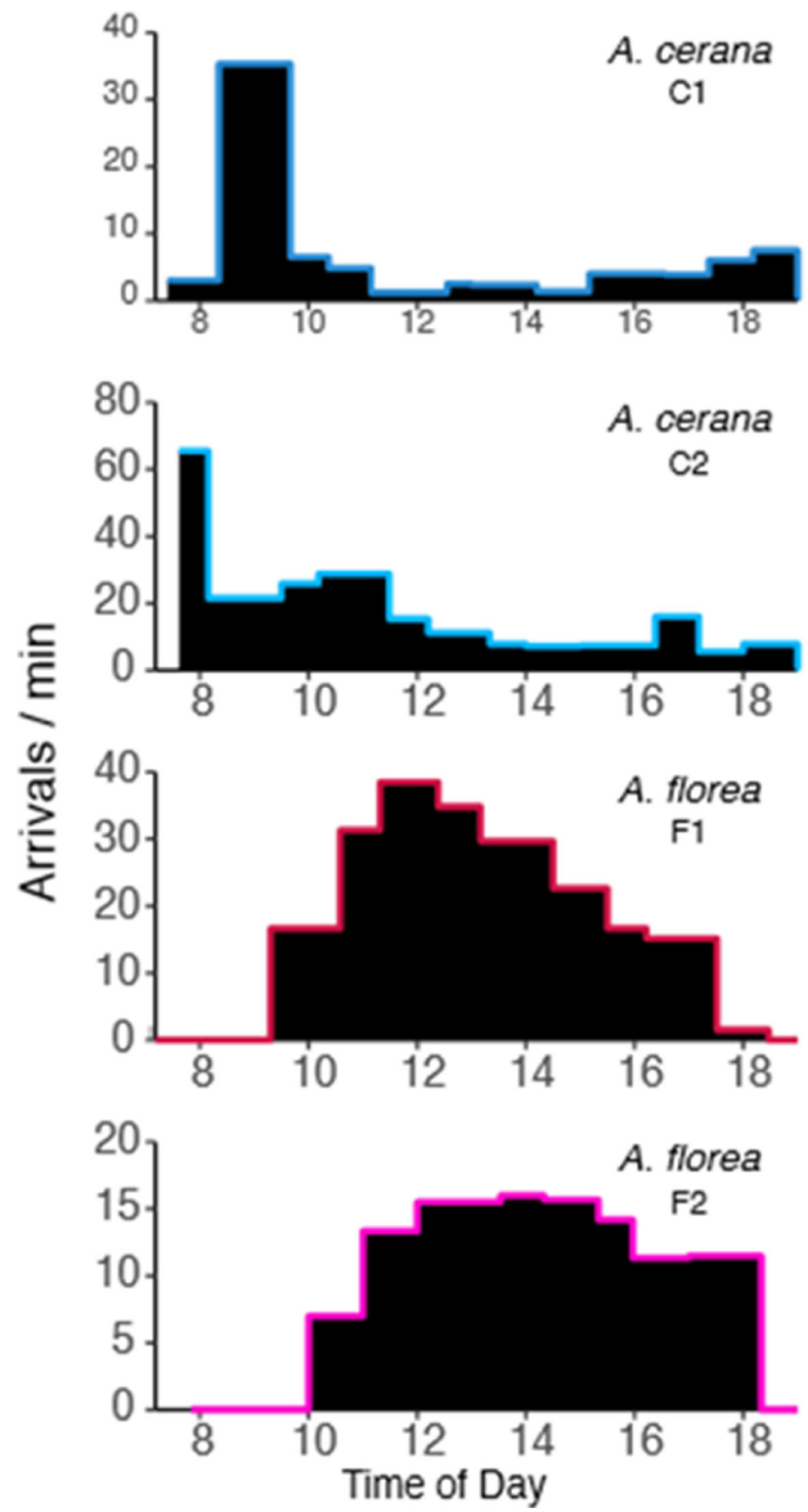

Figure 1. Foraging activity of A. cerana (colonies $\mathrm{C} 1$ and $\mathrm{C} 2$ ) and A. florea (colonies F1 and F2) in Bangalore during a 10-h daytime observation period on February 18th, 2017. Activity was determined from 6-min observation periods, then extrapolated for the hour. Sunrise and sunset were at 0641 hours and 1826 hours respectively. Note that $y$-axes are differently scaled. 

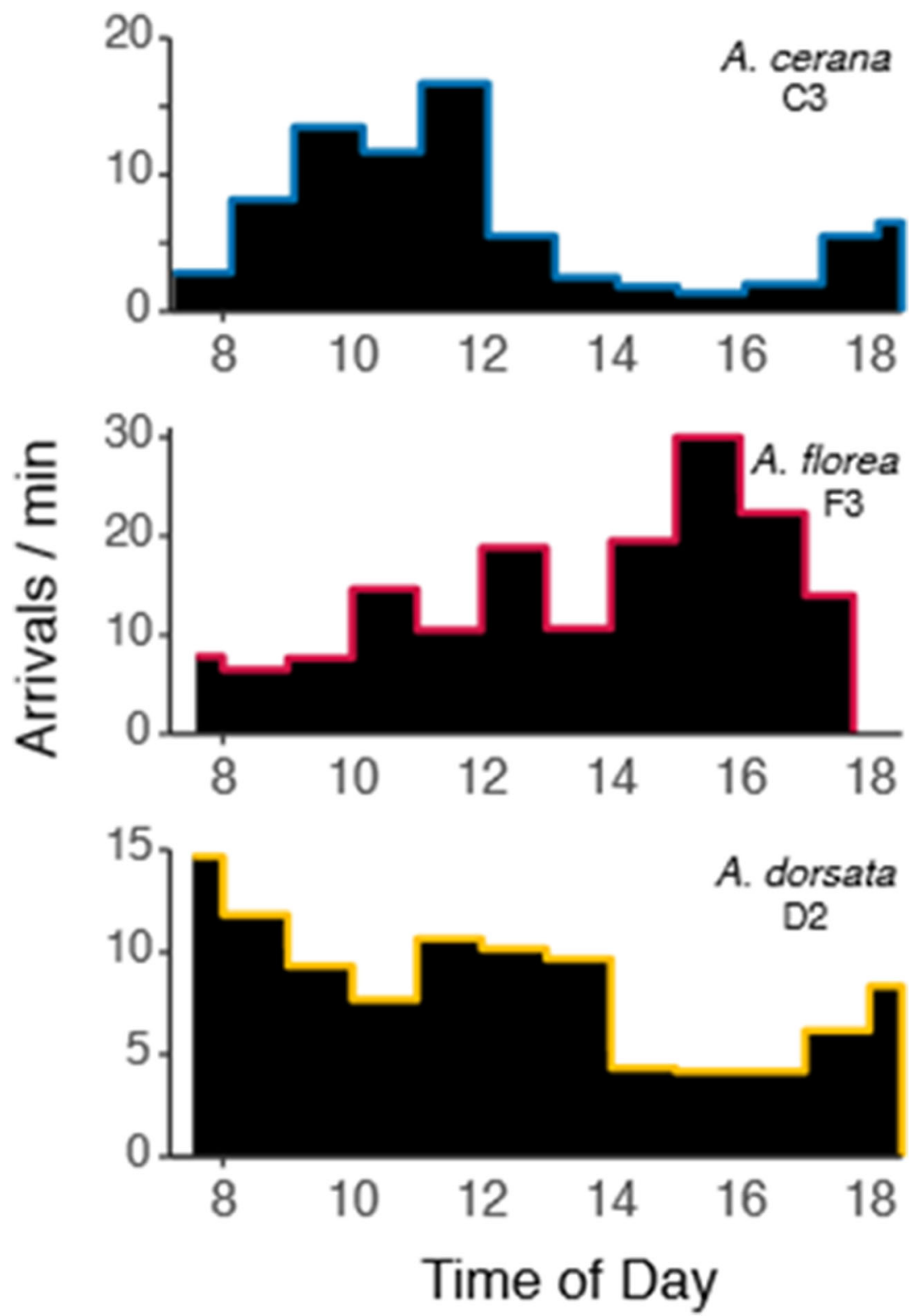

Figure 2. Foraging activity of A. cerana (colony C3), A. florea (colony F3), and A. dorsata (colony D2) in Bangalore during a 10-h daytime observation period on March 10th, 2017. Activity was determined from 6-min observation periods, then extrapolated for the hour. Sunrise and sunset were at 0630 hours and 1829 hours respectively. Note that $y$-axes are differently scaled.

considerable effort foraging outside the NCBS campus in urban areas (D1, D3, F3, F4), agricultural areas (C3), and seminatural areas (F1, F3, F4, C4).
An analysis of the habitat use of the bees in relation to the actual proportions of landscape types surrounding their colonies revealed that-at our specific study location and study 

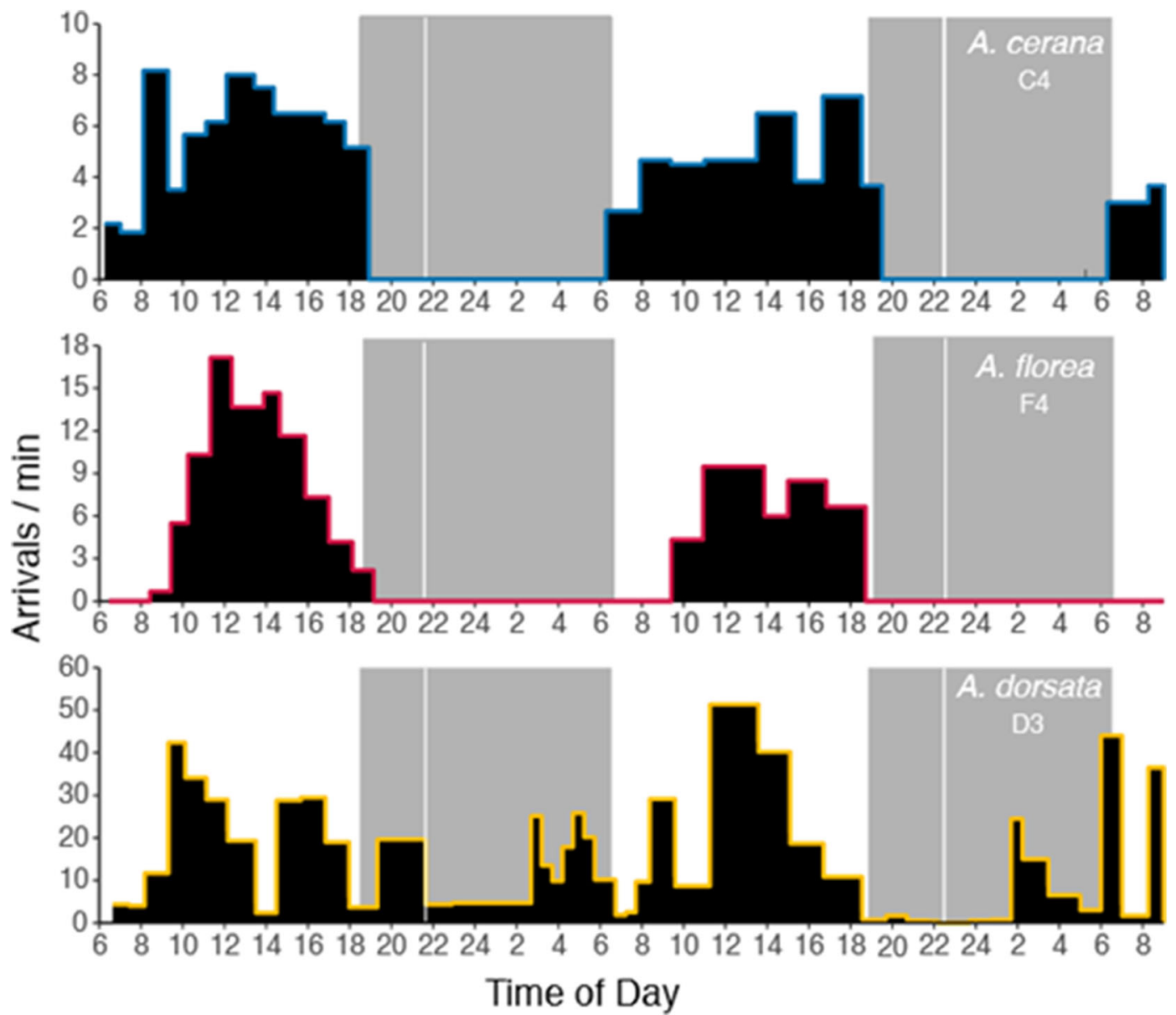

Figure 3. Foraging activity of A. cerana (colony C4), A. florea (colony F4), and A. dorsata (colony D3) in Bangalore during a 50-h observation period from March 5th to 7th, 2018. Activity was determined from 6-min observation periods, then extrapolated for the hour. Sunrise and sunset were at 0632 hours and 1829 hours respectively during this period. Gray areas demark nighttime hours (sun below the horizon) and white lines indicate moonrise times. There was a full moon on March 2nd. Note that $y$-axes are differently scaled.

time-all three species as a whole preferentially foraged in gardens over seminatural areas (forest and fallow land) and urban areas (Figure 8). Habitat use analyses for individual study colonies can be found in Supplementary Figure 5. Looking at each colony individually, we found that the habitat usage of each studied A. dorsata colony significantly differed from the usage expected based on the proportions of habitat in the surrounding landscape (D1-D3: $P<0.001$ for all; see Supplementary Table 2 for colony-specific test statistics), with each colony preferentially foraging in garden areas
(Figure S2). Three of the four A. florea colonies similarly differed in their habitat usage from expected (F1-F3: $P<=0.0001$ for all). However, of those three, only two preferentially foraged in garden areas (F2 and F3) with the third preferentially foraging in seminatural areas (F1; Figure S2). Similar to A. florea, three colonies of $A$. cerana significantly differed in their habitat usage from expected based on the surrounding landscape $(\mathrm{C} 1$ and $\mathrm{C} 2: P<$ $<0.0001$; C3: $P=0.04$ ), with all three preferring garden areas and $\mathrm{C} 3$ also showing a preference for agricultural lands (Figure S5). 


\subsection{Nocturnal behavior of $A$. dorsata}

Our results enable us to address two questions specific to $A$. dorsata's unique ability to forage throughout the night, at least when the moon is half full or larger. The first question is how important $A$. dorsata's nocturnal foraging is to its overall foraging activity. We found $A$. dorsata to be active on most, but not all, nights surrounding the full moon (Figure 9). When examining the average rate of foraging activity on those nights when they were active, we found that nocturnal foraging can sometimes constitute a significant portion of the colony's foraging efforts. For example, during the full moon period of March 5th6 th, the average recorded rates of $A$. dorsata's foraging activity during the day versus during the night were 20 and 10 arrivals per minute, respectively, leading us to estimate that $30 \%$ of their foraging took place during the night. However, the average recorded rates of $A$. dorsata's foraging activity during the March 31st full moon were 60 arrivals per minute during the day and only 5 arrivals per minute at night, suggesting nocturnal foraging constituted only $8 \%$ of $A$. dorsata's overall foraging effort in this period. This variability might reflect differences in resource availability on different nights.

The second question we can address is whether the spatial patterns of nocturnal foraging by A. dorsata differ from those during the day. We can only address the question of distance, given our lack of understanding of how this species signals direction in its dances at night. The data suggest that A. dorsata is capable of flying just as far at night as during the day, assuming $A$. dorsata foragers perceive distance similarly during the night as during the day, and possibly farther. Inferred flight distances were greater on the night of March 4th-5th than during the day on March 4th or March 5th, as seen through their longer median circuit duration $(3.0 \mathrm{~s}$ on the night of March 4th as compared to $2.1 \mathrm{~s}$ and $1.7 \mathrm{~s}$ during the day on March 4th and 5th respectively; Figure 9a). In contrast, we found that $A$. dorsata foraged closer to their colony on the night of March 30th-31st as compared to following day (median circuit durations: $2.0 \mathrm{~s}$ on the night of March 30th versus $3.7 \mathrm{~s}$ during the day on March 31st; Figure 9b).

\section{DISCUSSION}

In this study, we extend previous comparative studies of the foraging activity of Asian honey bees by (1) making parallel observations of the colony-level temporal foraging patterns of the study species, (2) including nighttime observations of $A$. dorsata in the study of their foraging activity, and (3) providing a more detailed picture of species' spatial foraging patterns. Overall, we found species differences in daily activity patterns, but no evidence that species differed in the types of habitats they preferred to forage in, though they did forage in those preferred habitats in ways that minimized spatial overlap.

Considering the temporal activity patterns of A. cerana, A. florea, and A. dorsata, we found in general that $A$. cerana and $A$. dorsata began foraging earlier in the day and ended foraging later in the day than did A. florea (Figures 1, 2, 3 , and 4). These patterns match those found in previous studies of these species (Dyer and Seeley 1991b; Oldroyd et al. 1992; Somanathan et al. 2009; Cui and Corlett 2016). Considering just daytime hours, these results provide some evidence of temporal partitioning of resources, in that A. florea remains active during the middle part of the day when A. dorsata and A. cerana become somewhat less active (Figures 1, 2, 3, and 4). In the case of $A$. dorsata, the reduced activity seen during midday hours could be partially due to thermal stress during the hottest hours of the day, which might prevent colonies from foraging extensively (Mardan and Kevan 2002; Kastberger et al. 2016). This pattern of activity may also be a result of the larger species abandoning floral resources that have become too depleted to sustain the energetic costs of foraging. As the species with the smallest workers and colonies, the tiny A. florea foragers may be able to continue making an energetic profit on such depleted resources (Schaffer et al. 1979; Schaffer et al. 1983). The small size of A. florea workers might similarly allow them to forage during the high midday heat, when other species might reduce their foraging due to limited thermoregulatory capacities, as has been seen in other social insect species (Pereboom and Biesmeijer 2003). Alternatively, studies of bees at a feeder suggest that smaller species can 

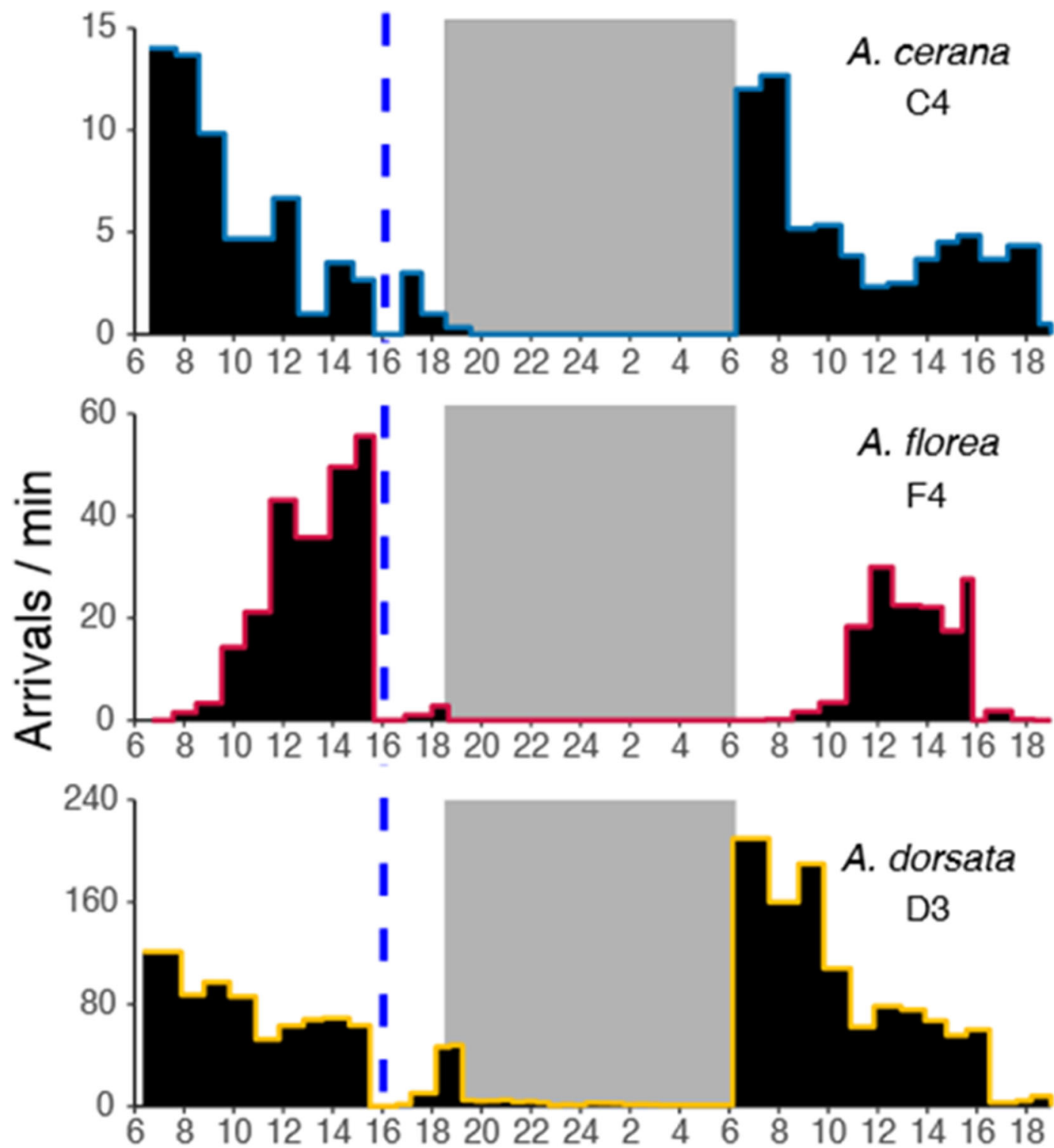

\section{Time of Day}

Figure 4. Foraging activity of A. cerana (colony C4), A. florea (colony F4) and A. dorsata (colony D3) in Bangalore during a 36-h observation period from March 30th to 31st, 2018. Activity was determined from 6-min observation periods, then extrapolated for the hour. Sunrise and sunset were at 0617 hours and 1832 hours respectively during this period. Gray areas demark nighttime hours (sun below the horizon). The night was completely lit by a full moon. Dashed blue lines indicate the start of a 1-h thunder shower. Note that $y$-axes are differently scaled.

monopolize resources better than larger species due to increased aggressiveness (Koeniger and
Vorwohl 1979). It is therefore possible that colonies avoided foraging in the same areas to 


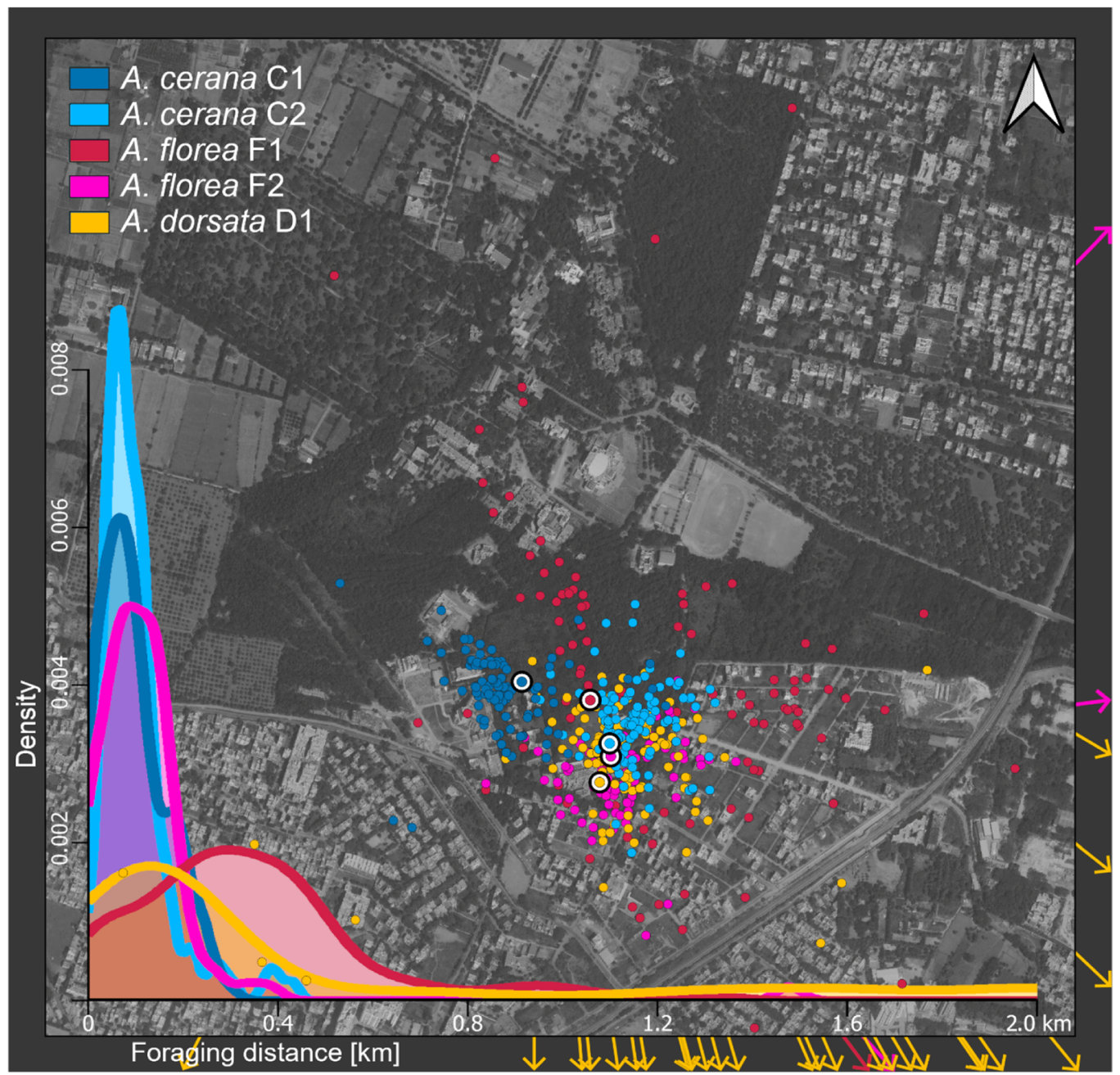

Figure 5. Foraging locations of $A$. cerana (colonies $\mathrm{C} 1$ and $\mathrm{C} 2$ ), A. florea (colonies F1 and F2), and A. dorsata (colony D1) around the NCBS in Bangalore, India, as inferred from waggle dances recorded between February 1st and 6th, 2017. Large circles depict colony locations and dots indicate foraging locations. Arrows point to foraging sites that lay outside the map. The figure in the lower left corner shows density curves of each colonies' foraging distance distribution. Its $x$-axis also serves as a scale bar for the map. See Supplementary Figure 2 for zoomed out map showing all foraging locations.

minimize the possibility of physically encountering each other on flowers in the field (Figures 5, 6, and 7).

The delayed initiation and early termination of foraging by $A$. florea can likely be explained by their unique nesting conditions and their small body size. A. florea builds their colonies in shady, well-protected environments, such as inside a bush or tree (Seeley et al. 1982; Dyer and Seeley 1991b; Oldroyd et al. 2008). This nesting habitat would result in sunlight reaching the colony later in the day and the nest warming up more slowly in the mornings as compared to the colonies of A. cerana, which can better regulate colony temperature due to living in enclosed cavities with parallel combs, or A. dorsata, which build colonies in more open habitats exposed to direct sunlight. In addition, the small size of $A$. florea would make them more sensitive to the temperature and illumination of the environment, such that they 


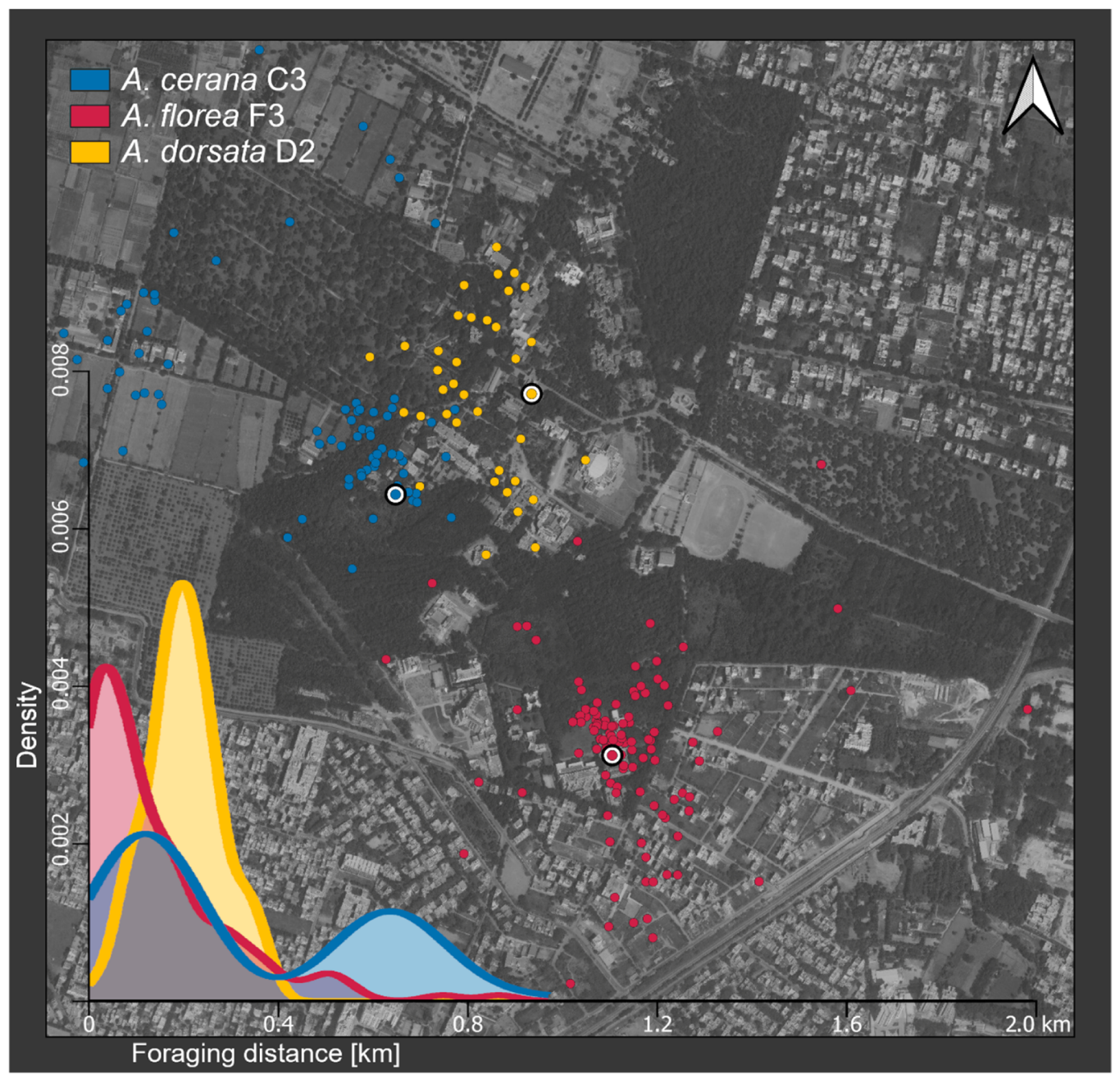

Figure 6. Foraging locations of A. cerana (colony C3), A. florea (colony F3), and A. dorsata (colony D2) around the NCBS in Bangalore, India, as inferred from waggle dances recorded between March 6th and 10th, 2017. Large circles depict colony locations and dots indicate foraging locations. The figure in the lower left corner shows density curves of each colonies' foraging distance distributions. Its $x$-axis also serves as a scale bar for the map. See Supplementary Figure 3 for zoomed out map showing all foraging locations.

would begin foraging at higher temperatures (Dyer and Seeley 1987; Cui and Corlett 2016) and light levels (Warrant 2008; Somanathan et al. 2009). In our study, A. cerana and A. dorsata were seen foraging in temperatures as low as $16^{\circ} \mathrm{C}$ during the night and pre-dawn hours, while $A$. florea generally was not active at temperatures below $20^{\circ} \mathrm{C}$ (as has been seen in other studies; Abrol 2006). Supporting the idea that temperature limitations might be responsible for the delayed start of $A$. florea in this study, on days where $A$. florea began foraging before 0800 hours (March 10, 2017 and March 30, 2018), the temperature was already over $21^{\circ} \mathrm{C}$ degrees by 0700 hours. In contrast, the temperature did not reach $21^{\circ} \mathrm{C}$ until 0800 hours or 0900 hours on all other days studied, corresponding with the initiation of foraging.

Previous studies on the foraging behavior of Asian honey bees have compared only their 


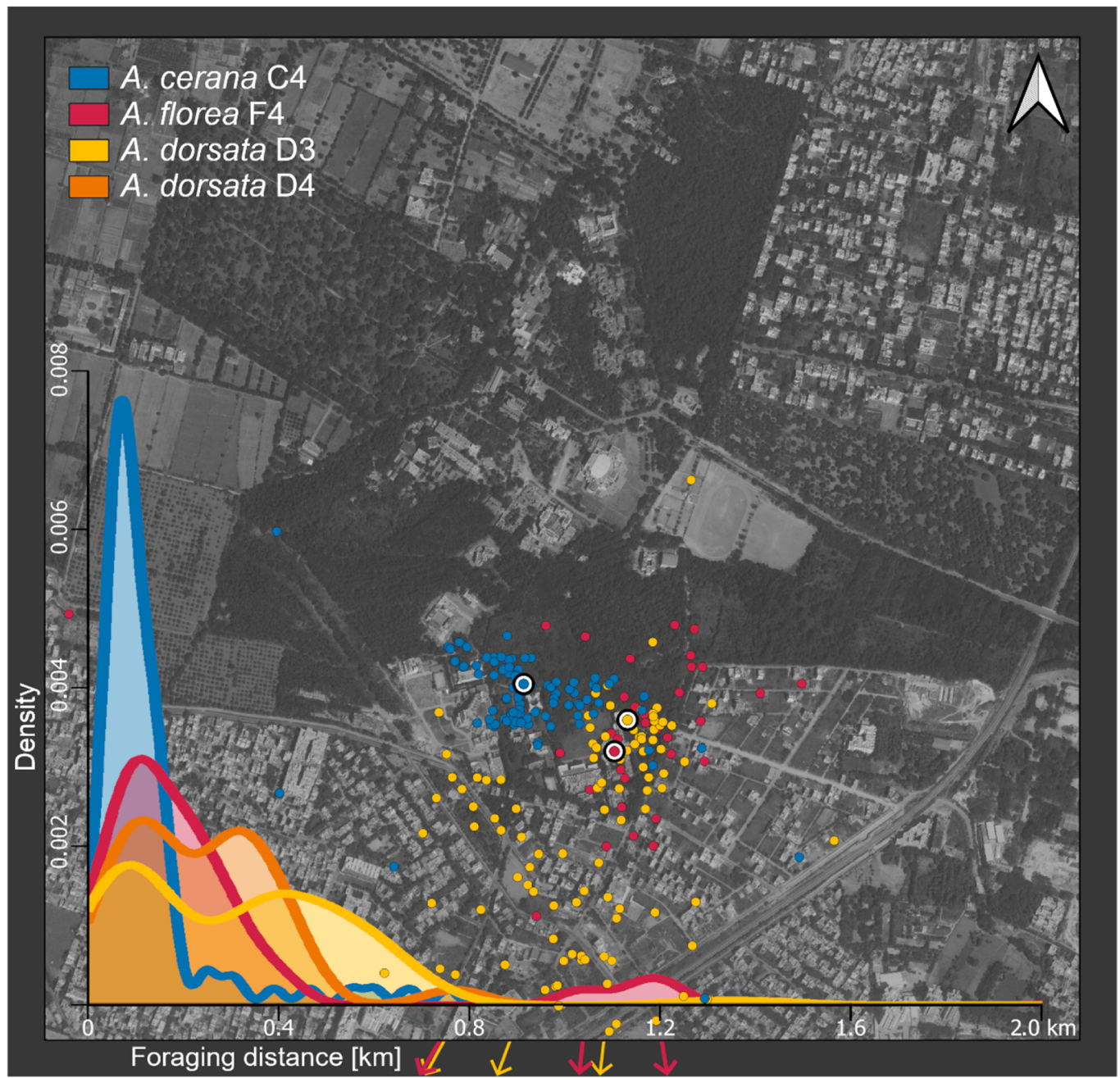

Figure 7. Foraging locations of A. cerana (colony C4), A. florea (colony F4), and A. dorsata (colonies D3 and D4) around the NCBS in Bangalore, India, as inferred from waggle dances recorded between March 5th and April 1st, 2018. Large circles depict colony locations and dots indicate foraging locations. Arrows point to foraging sites that lay outside the map. The figure in the lower left corner shows density curves of each colonies' foraging distance distribution. Its $x$-axis also serves as a scale bar for the map. For the A. dorsata colony D4 only, the distance information was available. See Supplementary Figure 4 for zoomed out map showing all foraging locations.

diurnal activity and foraging ranges. However, A. dorsata can fly at very low levels of ambient illumination, even during the night when the moon is partially full (Dyer 1985a; Somanathan et al. 2009). This ability to be active at night was found to be mostly unique to A. dorsata in our study, as even on nights with a full moon neither A. cerana nor A. florea were seen foraging much before the sun rose or for long after it set (Figures 3 and 4). In addition, we observed the intriguing behavior that $A$. dorsata was even able to forage in the hours after sunset but before moonrise (Figure 3). During this period, there would have been small amounts of ambient light and sky polarization available from the sun during astronomical twilight (though this did end before moonrise) as well as light from artificial light sources on the NCBS campus and the sky glow of Bangalore. A. dorsata therefore is capable of flying using solely these limited light sources even 
A. cerana

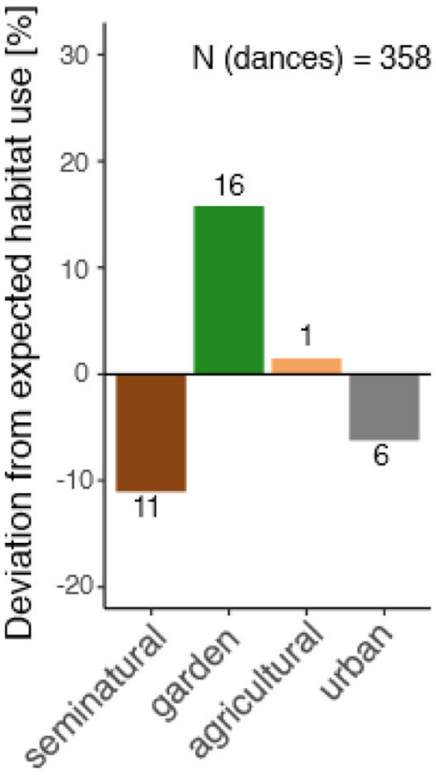

A. florea

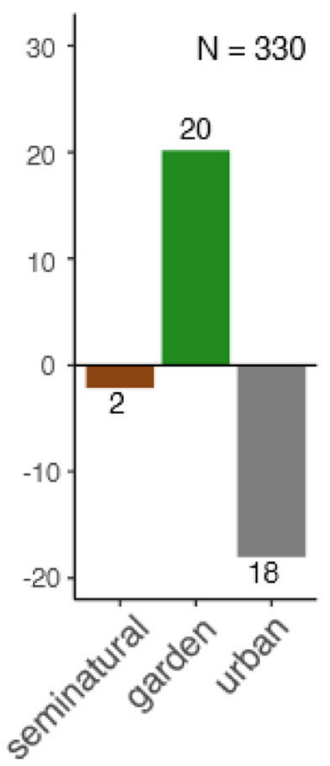

A. dorsata

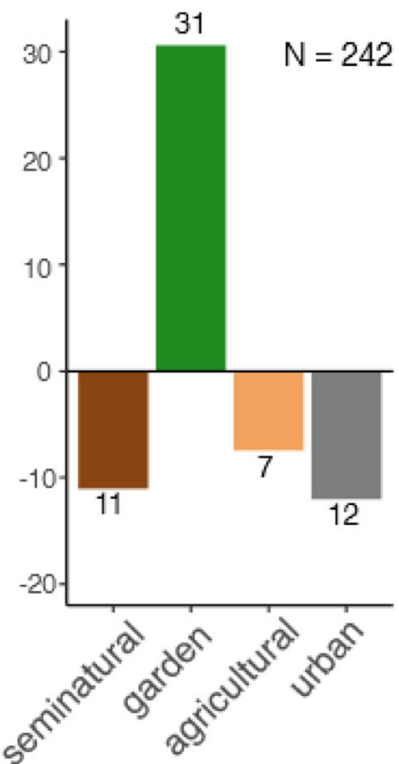

\section{Landscape type}

Figure 8. Deviations from expected habitat use of A. cerana, A. florea, and A. dorsata foraging at the NCBS and GKVK campuses and surroundings in Bangalore, India. The expected random habitat use was calculated based on the proportions of each habitat type within the $90 \%$ foraging range of each species calculated within this study. The observed and expected values were averaged over four colonies per species (three colonies in A. dorsata) and over three observation periods. See supplementary Figure 5 for individual colony habitat use.

when the moon has not yet risen. Sky glow from cities has also been shown to reduce polarization of lunar light (Kyba et al. 2011), though, suggesting that such artificial light sources might be beneficial in some regards (extending the times at which nocturnal activity is possible) but negative in others (by making navigation on moonlit nights harder). While A. cerana was occasionally observed foraging in the $30 \mathrm{~min}$ prior to sunrise and after sunset (Figures 3 and 4), this activity took place during astronomical twilight when small amounts of light and sky polarization from the sun are available and therefore could not be considered nocturnal activity.

One likely contributing factor to A. dorsata's ability to fly at night is the fact that $A$. dorsata workers are larger than both A. cerana and A. florea, with correspondingly larger eyes and ocelli, which enable higher sensitivity without sacrificing acuity (Warrant 2008; Somanathan et al. 2009; Streinzer et al. 2013). Future research is needed to better understand how $A$. dorsata is capable of flying in very low-light levels, as well as to identify the minimum amount of light A. dorsata needs to be active at night. Special attention should be paid to the effects of artificial light sources (such as sky glow) on A. dorsata's nocturnal behavior, as our studies suggests that it can provide sufficient illumination for $A$. dorsata to fly though more research is needed to draw broad conclusions.

This study is the first to examine the contribution of $A$. dorsata's nocturnal foraging to its overall daily activity. On full moon nights, up to $30 \%$ of $A$. dorsata 's activity occurred during the night (Figures 1 and 2). Not only was there a lot of traffic coming and going from the colony, but this activity can clearly be related to foraging, given that virtually all incoming bees were carrying pollen loads, and we observed a large amount of recruitment dancing during the night (Figure 9). Interestingly, we found that the amount of 

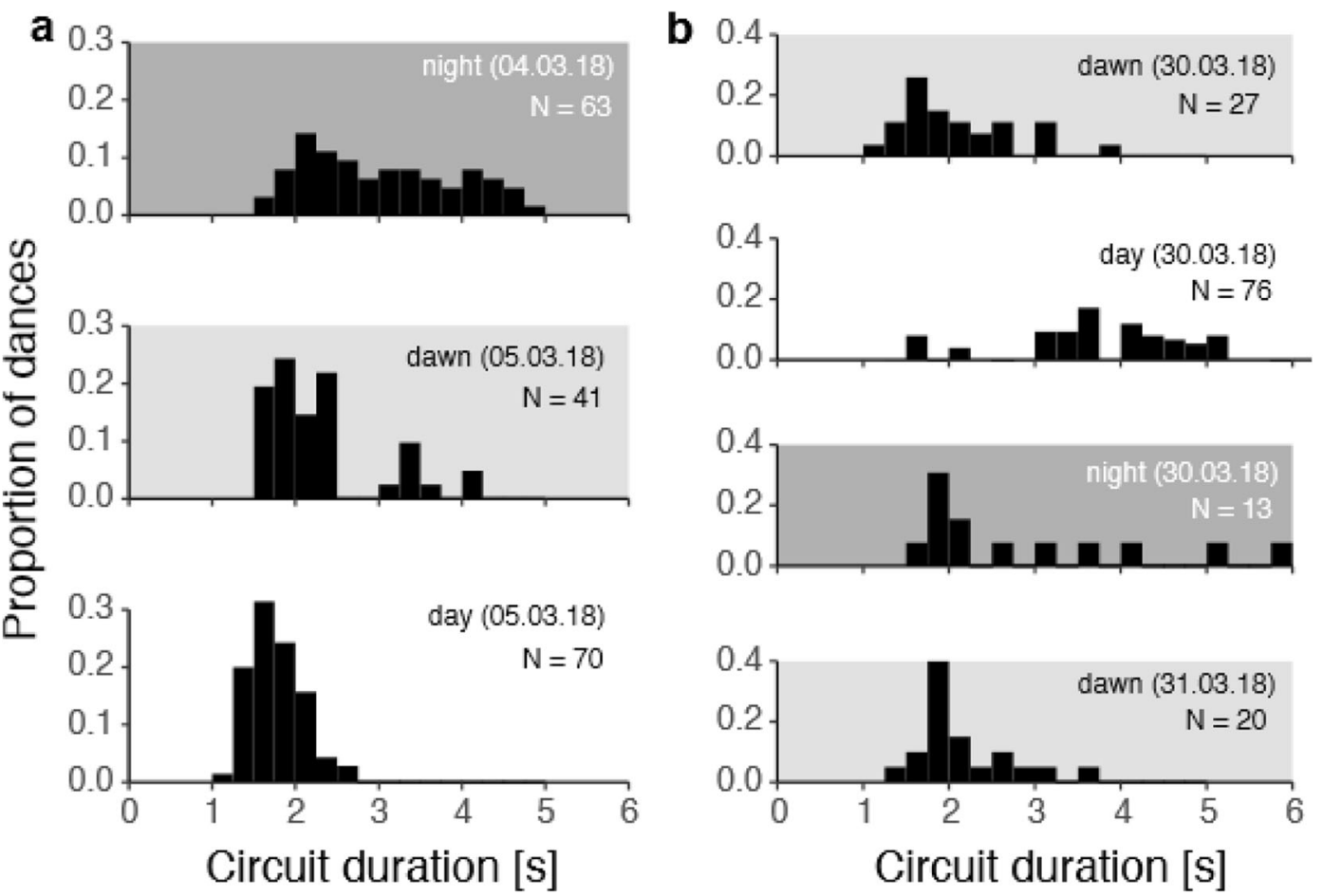

Figure 9. Distributions of waggle dance circuit durations of A. dorsata colony D3 during night, dawn, and day a from March 4th to 5th, 2018 and b from March 29th to 31st, 2018.

nocturnal activity varied extensively on full moon nights, even though all of the nights studied were rainless and between $16^{\circ} \mathrm{C}$ and $25 \mathrm{C}$ degrees (field observations). It is possible that factors such as resource availability or colony food stores, neither of which we were able to quantify, might be responsible for the differences in nocturnal activity we observed here. Including nocturnal activity will be important in future studies of A. dorsata's foraging behavior, as it can significantly contribute to the overall activity of the colony studied here. These future studies should examine which resources A. dorsata exploits during the night and factors influencing colony investment in nocturnal activity, as well as quantify the nectar and pollen contributions of nocturnal foragers to the colony's overall energy budget.

Interestingly, based upon a comparison of the circuit durations we measured in A. dorsata dances, bees seemed to forage equally as far or farther at night as compared to the day (Figure 9). The differences in median circuit duration suggest that the bees were possibly foraging in different places during the night versus during the day. However, our study did analyze circuit duration instead of waggle run duration when determining foraging distance. While circuit duration has historically been used, waggle run duration provides a more accurate distance signal due to variation in the return phase of the dance depending on dancer motivation (Seeley et al. 2000). Longer return phases due to lower motivation could artificially inflate the circuit duration and therefore the derived foraging distance measured. Differences in resource quality between diurnal and nocturnal resources could therefore lead to misleading differences in foraging distances calculated from these time periods. While we were unable to isolate and analyze waggle run duration of nocturnal dances in our study due to video quality limitations, future studies should carefully consider the costs and benefits of analyzing waggle run duration versus circuit duration in their foraging mapping efforts.

Comparison of inferred flight distance during night and day is further complicated because it 
hinges on the assumption that nocturnal and diurnal foragers measure flight distance in the same way. Studies of A. mellifera have shown that the honey bee odometer is based upon optic flow (Esch and Burns 1996; Esch et al. 2001), and optic flow has also been implicated in the odometry of nocturnal sweat bees (Baird et al. 2011). Lowlight conditions during nocturnal foraging might change the perception of optic flow while flying, which could distort the representation of distance in subsequent dances. Without direct evidence about how illumination affects the mapping of optic flow onto bees' distance estimations, we can nevertheless speculate that it may be harder for bees to detect visual texture at night; thus, they may experience lower optic flow signals over portions of their foraging route (Srinivasan 1992; Esch et al. 2001). If so, then we would expect bee dances to be more likely to underestimate than to overestimate the actual distances flown at night as compared to the day (Esch et al. 2001). This only strengthens our conclusion, based on the measured distance signals in the dances, that A. dorsata's flight distances at night can be just as great as during the day. It seems, then, that there are likely not strict differences between diurnal and nocturnal foraging in terms of their foraging distance or activity though more comparisons are needed.

Studying the nocturnal foraging behavior of A. dorsata is made more complicated by the fact that we currently do not know how bees convey directional information in their dances at night. Though it has been well established that honey bees use the sun's azimuth and sky polarization as reference points for their diurnal dances, it is currently unclear what reference point they use in nocturnal dances when the sun is not visible. Since there is evidence that they do not use the moon as a reference, an interesting future direction would be to correlate changes in nocturnal dance angles with the extrapolated solar azimuth to determine their referencing method. We were unable to determine this in our study due to the large gaps in foraging activity throughout our observation nights (Figures 3 and 4), which prevented us from being able to correlate dance angles and the sun's position (actual or extrapolated) throughout the night. However, with additional observations of nocturnal dancing, we believe this question could be readily answered. Understanding how bees reference their dances at night, together with a firm grasp on how bees perceive distance at night, would allow for more in-depth forage mapping than could be done in this study, such as determining the number of patches exploited at night and if the same resources are used during the day and night.

Apis dorsata's ability to fly at low-light levels is expected to give it a considerable advantage over other honey bee species by allowing it to escape from competition during the nighttime hours. At least some of their nocturnal foraging exploits floral species that are available in the evening after sunset and in the morning before sunrise (Dyer 1985a), and so A. dorsata would be the only honey bee species in this habitat to be able to fully exploit such resources. Nocturnally active bee species, including Xylocopa tenuiscapa and $A$. dorsata, have been shown to forage on nocturnal or crepuscular blooming plants in India and other parts of Southeast Asia (Rao et al. 2001; Somanathan and Borges 2001; Koeniger et al. 2010), suggesting that there are strictly night-blooming resources that $A$. dorsata is able to exploit without competition from other honey bee species, as well.

This study highlights that at least some temporal partitioning exists among the Asian honey bees studied here. The most striking example is the monopoly A. dorsata holds over nocturnal resources (among Apis species at least), but there is also evidence that $A$. florea is more active during midday and early afternoon (although, as mentioned, this may be because A. dorsata and A. cerana are superior competitors for morning resources). In contrast, we found limited evidence for spatial partitioning of the landscapes. The forage maps provide no compelling evidence that the three species were generally foraging in different areas in the landscape; instead, all seemed to primarily forage in garden areas (Figure 8). However, within these garden areas, we did find that colonies tended to exploit different patches, suggesting small-scale spatial partitioning (Figures 5, 6, and 7). This result is not surprising considering the garden areas contained many cultivated flowering plants and were therefore likely 
to be rich in resources of different kinds. These resources might have allowed colonies to partition the garden areas in ways that minimize competition and are related to species differences in flight range. Similarly, it is unsurprising that bees foraged in urbanized areas less than would be expected if they were foraging randomly as these areas are primarily composed of concrete buildings and roads. Use of agricultural and seminatural landscapes, though, are likely to be highly seasonal. One would expect foraging on agricultural lands to be high if the crops grown are both insect pollinated and currently flowering, and foraging to be higher in seminatural areas if floral resources are currently flowering. During the months of February and March in Bangalore, however, there are few natural plants flowering (Santhosh and Basavarajappa 2016). In addition, most of the agricultural fields located within the measured ranges are mango orchards, and mango was similarly not flowering during this study (Ravishankar et al. 1979; Parmar et al. 2012). That said, the slight preferences for seminatural habitats seen in the A. florea and A. cerana colonies observed in the February 2017 and March-April 2018 observation period suggests there might have been a few floral resources available during those periods (Figure S2). Overall, the foraging patterns seen in this study are therefore likely a result at least in part of the current availability of resources in this particular environment. These results suggest that gardens in cities can be extremely important foraging habitat for Asian honey bees, as they often are for many bee species (Stelzer et al. 2010; Kaluza et al. 2016). In addition, it complements findings from surveys of solitary bees and bumblebees that suggest urban gardens contain higher species diversity that surrounding landscapes (Martins et al. 2017; Theodorou et al. 2020). Future studies should investigate the seasonal habitat use of these species to determine if specific habitat preferences occur when floral resources are more plentiful throughout the environment.

This study provides a unique perspective into the activity and foraging patterns of three Asian honey bee species by including nocturnal behavior in the study of $A$. dorsata's activity. It strengthens previous investigations into the activity and foraging patterns of these species and paves the way for future investigations into their foraging ecology, particularly that of A. dorsata. As Apis species are extremely important to both tropical forests and crops, the improved understanding of their foraging ecology this study provides is a vital first step in the maintenance and conservation of tropical ecosystems.

\section{SUPPLEMENTARY INFORMATION}

The online version contains supplementary material available at https://doi.org/10.1007 /s13592-020-00839-1.

\section{ACKNOWLEDGMENTS}

We are grateful to Norbert Schneider and Johann Kaderschabek from the workshop of the University of Würzburg for manufacturing equipment needed to observe Asian honey bees. We would like to thank two anonymous reviewers for their helpful comments on this manuscript.

\section{AUTHOR CONTRIBUTIONS}

All authors were involved in the planning of the study. A.B. provided access to facilities and bee colonies. P.L.K., A.M.Y., B.R., and F.C.D. made foraging activity observations. P.L.K., B.R., and A.M.Y recorded and analyzed waggle dances. B.R. and P.L.K. analyzed and visualized the data. A.M.Y. led the writing of the manuscript. All authors contributed to the final paper.

\section{FUNDING}

A.M.Y. was supported by a National Science Foundation Graduate Research Fellowship (DGE-1848739). P.L.K. and B.R. were supported by fellowships and I.S.D. was supported by a travel grant, respectively, of the Bavarian-Indian Centre. A.B. acknowledges support of the Department of Atomic Energy, Government of India, under 472 project no. 12-R\&D-TFR-5.04-0800. Research in A.B.'s lab is supported by NCBS/ TIFR institutional funds (No. 12P4167). 


\section{DATA AVAILABILITY}

The datasets generated during and/or analyzed during the current study are available from the corresponding author on reasonable request.

\section{COMPLIANCE WITH ETHICAL STANDARDS}

Conflict of interest The authors declare that they have no conflicts of interest.

\section{Ethics approval Not applicable}

\section{Consent to participate Not applicable}

\section{Consent for publication Not applicable}

Code availability The code generated during the current study are available from the corresponding author on reasonable request.

Modèles de butinage temporel et spatial de trois espèces d'abeilles asiatiques à Bangalore, en Inde.

Abeilles asiatiques / recherche de nourriture spatiotemporelle / coexistence / partage des ressources.

Die zeitlichen und räumlichen Muster des Sammelverhaltens von drei asiatischen Honigbienenarten in Bangalore, Indien.

Asiatische Honigbienen / raumeitliches Sammelverhalten / Koexistenz / Resourcenaufteilung.

\section{REFERENCES}

Abrol, D. P. (2006) Factors influencing flight activity of Apis florea $F$, an important pollinator of Daucus carota L. J. Apic. Res. 45 (2), 2-6

Baird, E., Kreiss, E., Wcislo, W., Warrant, E., Dacke, M. (2011) Nocturnal insects use optic flow for flight control. Biol. Lett. 7 (4), 499-501

Bakker, D. R. (2001) Foraging and habitat selection by two species of honey bee near Lore Lindu National Park in Sulawesi, Indonesia. Dissertation, University of Guelph
Batra, P. (2003) Landscape foraging ecology of giant honey bees, Apis dorsata, in an Indian forest. Dissertation, Michigan State University

Bawa, K. S. (1990) Plant-pollinator interactions in tropical rain forests. Annu. Rev. Ecol. Syst. 21 (1), 399-422

Beekman, M., Ratnieks F. L. W. (2000) Long-range foraging by the honey-bee, Apis mellifera L. Funct. Ecol. 14 (4),490-496

Bhagavan, H., Muthmann, O., Brockmann, A. (2016) Structural and temporal dynamics of the bee curtain in the open-nesting honey bee species, Apis florea. Apidologie 47 (6), 749-758

Brown, M. J., Dicks, L. V., Paxton, R. J., et al. (2016) A horizon scan of future threats and opportunities for pollinators and pollination. PeerJ, 4, e2249

Cariveau, D. P., Nayak, G. K., Bartomeus, I., Zientek, J., Ascher, J. S., Gibbs, J., Winfree, R. (2016) The allometry of bee proboscis length and its uses in ecology. PLoS One 11 (3), e0151482

Corlett, R. T. (2004) Flower visitors and pollination in the Oriental (Indomalayan) Region. Biol. Rev. 79 (3), 497-532

Couvillon, M. J., Pearce, F. C. R., Accleton, C., Fensome, K. A., Quah, S. K., Taylor, E. L., Ratnieks, F. L. (2015) Honey bee foraging distance depends on month and forage type. Apidologie 46 (1), 61-70

Cui, Q., Corlett, R. T. (2016) Seasonal and diurnal patterns of activity in honeybees (Apis spp.) on the northern edge of the Asian tropics; their implications for the climate-change resilience of pollination. Trop. Conserv. Sci. 9 (3), 1940082916667142

Dainese, M., Martin, E. A., Aizen, M. A., et al. (2019) A global synthesis reveals biodiversity-mediated benefits for crop production. Sci. Adv. 5, eaax0121

Donaldson-Matasci, M. C., Dornhaus, A. (2012) How habitat affects the benefits of communication in collectively foraging honey bees. Behav. Ecol. Sociobiol. 66 (4), 583-592

Dornhaus, A., Chittka, L. (2004) Why do honey bees dance? Behav. Ecol. Sociobiol. 55 (4), 395-401

Dornhaus, A., Klügl, F., Oechslein, C., Puppe, F., Chittka, L. (2006) Benefits of recruitment in honey bees: effects of ecology and colony size in an individual-based model. Behav. Ecol. 17 (3), 336-344

Dyer, F. C. (1985a) Nocturnal orientation by the Asian honey bee, Apis dorsata. Anim. Behav. 33 (3), 769-774

Dyer, F. C. (1985b) Mechanisms of dance orientation in the Asian honey bee Apis florea L. J. Comp. Physiol. A. 157 (2), 183-198

Dyer, F. C. (2002) The biology of the dance language. Annu. Rev. Entomol. 47 (1), 917-949

Dyer, F. C., Seeley, T. D. (1987) Interspecific comparisons of endothermy in honey-bees (Apis): deviations from the expected size-related patterns. J. Exp. Biol. 127 (1), 1-26

Dyer, F. C., Seeley, T. D. (1991a) Dance dialects and foraging range in three Asian honey bee species. Behav. Ecol. Sociobiol., 28 (4), 227-233 
Dyer, F. C., Seeley, T. D. (1991b) Nesting behavior and the evolution of worker tempo in four honey bee species. Ecology 72 (1), 156-170

Dyer, F. C., Seeley, T. D. (1994) Colony migration in the tropical honey bee Apis dorsata f. (Hymenoptera: Apidae ). Insect. Soc. 41 (2), 129-140

Esch, H., Burns, J. (1996) Distance estimation by foraging honeybees. J. Exp. Biol. 199 (1), 155-162

Esch, H. E., Zhang, S., Srinivasan, M. V., Tautz, J. (2001) Honeybee dances communicate distances measured by optic flow. Nature 411 (6837), 581

Freitas, B. M., Imperatriz-Fonseca, V. L., Medina, L. M., Kleinert, A. D. M. P., Galetto, L., Nates-Parra, G., Quezada-Euán, J. J. G. (2009) Diversity, threats and conservation of native bees in the Neotropics. Apidologie 40 (3), 332-346

Greenleaf, S. S., Williams, N. M., Winfree, R., Kremen, C. (2007) Bee foraging ranges and their relationship to body size. Oecologia 153 (3), 589-596

He, X., Wang, W., Qin, Q., Zeng, Z., Zhang, S., Barron, A. B. (2013) Assessment of flight activity and homing ability in Asian and European honey bee species, Apis cerana and Apis mellifera, measured with radio frequency tags. Apidologie 44 (1), 38-51

Hepburn, H. R., Radloff, S. E. (Eds.) (2011) Honeybees of Asia. Springer Science \& Business Media

Hung, K. L. J., Kingston, J. M., Albrecht, M., Holway, D. A., \& Kohn, J. R. (2018). The worldwide importance of honey bees as pollinators in natural habitats. Pro. Royal Soc. B 285 (1870), 20172140

Kaluza, B. F., Wallace, H., Heard, T. A., Klein, A. M., Leonhardt, S. D. (2016) Urban gardens promote bee foraging over natural habitats and plantations. Ecol. Evol. 6 (5), 1304-1316

Kastberger, G., Waddoup, D., Weihmann, F., Hoetzl, T. (2016) Evidence for Ventilation through Collective Respiratory Movements in Giant Honeybee (Apis dorsata) Nests. PLoS One 11 (8)

Klein, A. M., Vaissiere, B. E., Cane, J. H., SteffanDewenter, I., Cunningham, S. A., Kremen, C., Tscharntke, T. (2007) Importance of pollinators in changing landscapes for world crops. Proc. R. Soc. B Biol. Sci. 274 (1608), 303-313

Koeniger, N., Vorwohl, G. (1979) Competition for food among four sympatric species of Apini in Sri Lanka (Apis dorsata, Apis cerana, Apis florea and Trigona iridipennis ). J. Apic. Res. 18 (2), 95-109

Koeniger, N., Koeniger, G., Tingek, S. (2010) Honey bees of Borneo: exploring the centre of Apis diversity. Borneo: Natural History Publications

Kohl, P. L., Thulasi, N., Rutschmann, B., George, E. A., Steffan-Dewenter, I., Brockmann, A. (2020) Adaptive evolution of honeybee dance dialects. Proc. Royal Soc. B 287 (1922), 20200190

Kyba, C. C. M., Ruhtz, T., Fischer, J., Hölker, F. (2011) Lunar skylight polarization signal polluted by urban lighting. J. Geophys. Res. Atmos. 116 (D24)
Lindauer, M. (1956) Über die Verständigung bei indischen Bienen. Z. Vgl. Physiol. 38 (6), 521-557

Lindauer, M. (1971) Communication among social bees. Harvard University Press, Cambridge

Liow, L. H., Sodhi, N. S., Elmqvist, T. (2001) Bee diversity along a disturbance gradient in tropical lowland forests of South-east Asia. J. Appl. Ecol. 38 (1), 180-192

Mardan, M., Kevan, P. G. (2002) Critical temperatures for survival of brood and adult workers of the giant honeybee, Apis dorsata (Hymenoptera: Apidae). Apidologie 33 (3), 295-301

Martins, K. T., Gonzalez, A., Lechowicz, M. J. (2017) Patterns of pollinator turnover and increasing diversity associated with urban habitats. Urban Ecosyst. 20 (6), 1359-1371

Michener, C. D. (1979) Biogeography of the bees. Ann. Missouri Bot. 277-347

Mukherjee, R., Deb, R., Devy, S. M. (2019) Diversity matters: Effects of density compensation in pollination service during rainfall shift. Ecol. Evol, 9 (17), 97019711

Oldroyd, B. P., Nanork, P. (2009) Conservation of Asian honey bees. Apidologie 40 (3), 296-312

Oldroyd, B. P., Wongsiri, S. (2006) Asian honey bees: biology, conservation, and human interactions. Harvard University Press

Oldroyd B.P., Rinderer T.E.,Wongsiri S. (1992) Pollen resource partitioning by Apis dorsata, A. cerana, A andreniformis and $A$. florea in Thailand, J. Apic. Res. 31, 3-7

Oldroyd, B. P., Gloag, R. S., Even, N., Wattanachaiyingcharoen, W., Beekman, M. (2008) Nest site selection in the open-nesting honeybee Apis florea. Behav. Ecol. Sociobiol. 62 (10), 1643-1653

Parmar, V. R., Shrivastava, P. K., Patel, B. N. (2012) Study on weather parameters affecting the mango flowering in south Gujarat. J. Agrometeorol. 14, 351-353

Pereboom, J. J. M., Biesmeijer, J. C. (2003) Thermal constraints for stingless bee foragers: the importance of body size and coloration. Oecologia. 137 (1), 42-50

Potts, S. G., Biesmeijer, J. C., Kremen, C., Neumann, P., Schweiger, O., Kunin, W. E. (2010) Global pollinator declines: trends, impacts and drivers. Trends Ecol. Evol. 25 (6), 345-353

Price, R. I., Grüter, C. (2015) Why, when and where did honey bee dance communication evolve?. Front. Ecol. Evol. 3, 125

Punchihewa, R. W. K., Koeniger, N., Kevan, P. G., Gadawski, R. M. (1985) Observations on the dance communication and natural foraging ranges of Apis cerana, Apis dorsata and Apis florea in Sri Lanka. J. Apic. Res. 24 (3), 168-175

Rao, S. P., Atluri, J. B., Reddi, C. S. (2001) Intermittent mass blooming, midnight anthesis and rockbee pollination in Pterocarpus santalinus (Fabaceae). Nord. J. Bot. 21 (3), 271-276 
Ravishankar, H., Rao, M. M., Bojappa, K. M. (1979) Fruitbud differentiation in mango 'Alphonso' and 'Totapuri' under mild tropical rainy conditions. Sci. Hortic. 10 (1), 95-99

Requier, F., Garnery, L., Kohl, P. L., Njovu, H. K., Pirk, C. W., Crewe, R. M., \& Steffan-Dewenter, I. (2019) The conservation of native honey bees is crucial. Trends Ecol. Evol. 34, 789-798

Rinderer, T. E., Marx, B. D., Gries, M., \& Tingek, S. (1996) A scientific note on stratified foraging by Sabahan bees on the yellow flame tree (Peltophorum pferocarpum ). Apidologie, 27 (5), 423-425

Roubik, D. W. (1990) Niche pre-emption in tropical bee communities: A comparison of Neotropical and Malesian faunas, in Natural History of Social Wasps and Bees in Equatorial Sumatra. S. Sakagami, R. Ohgushi and D. W. Roubik (ed.). Hokkaido University Press, Sapporo

Ruttner, F. (1988) Biogeography and taxonomy of honeybees. Springer-Verlag, Berlin

Santhosh, S., Basavarajappa, S. (2016) Study on nectar plants of few butterfly species at agriculture ecosystems of Chamarajanagar District, Karnataka, India. Int. J. Entomol. Res. 1 (5), 40-48

Schaffer, W. M., Jensen, D. B., Hobbs, D. E., Gurevitch, J., Todd, J. R., Schaffer, M. V. (1979) Competition, foraging energetics, and the cost of sociality in three species of bees. Ecology 60 (5), 976-987

Schaffer, W. M., Zeh, D. W., Buchmann, S. L., Kleinhans, S., Schaffer, M. V., Antrim, J. (1983) Competition for nectar between introduced honey bees and native North American bees and ants. Ecology 64 (3), 564577

Seeley, T. D., Seeley, R. H., \& Akratanakul, P. (1982) Colony defense strategies of the honeybees in Thailand. Ecol. Monogr. 52 (1), 43-63

Seeley, T. D., Mikheyev, A. S., Pagano, G. J. (2000) Dancing bees tune both duration and rate of wagglerun production in relation to nectar-source profitability. J. Comp. Physiol. A. 186 (9), 813-819

Somanathan, H., Borges, R. M. (2001) Nocturnal Pollination by the Carpenter Bee Xylocopa tenuiscapa (Apidae) and the Effect of Floral Display on Fruit Set of Heterophragma quadriloculare (Bignoniaceae) in India 1. Biotropica, 33 (1), 78-89

Somanathan, H., Warrant, E. J., Borges, R. M., Wallén, R., Kelber, A. (2009) Resolution and sensitivity of the eyes of the Asian honeybees Apis florea, Apis cerana and Apis dorsata. J. Exp. Biol. 212 (15), 2448-2453
Srinivasan, M. V. (1992) How bees exploit optic flow: behavioural experiments and neural models. Philos. Trans. Royal Soc. Lond. B Biol. Sci. 337 (1281), 253-259

Stelzer, R. J., Chittka, L., Carlton, M., Ings, T. C. (2010) Winter active bumblebees (Bombus terrestris) achieve high foraging rates in urban Britain. PLoS One, 5 (3)

Stewart, A. B., Sritongchuay, T., Teartisup, P., Kaewsomboon, S., Bumrungsri, S. (2018) Habitat and landscape factors influence pollinators in a tropical megacity, Bangkok, Thailand. PeerJ 6, e5335

Streinzer, M., Brockmann, A., Nagaraja, N., Spaethe, J. (2013) Sex and caste-specific variation in compound eye morphology of five honeybee species. PLoS One 8 (2)

Theodorou, P., Radzevičiūtè, R., Lentendu, G., et al. (2020) Urban areas as hotspots for bees and pollination but not a panacea for all insects. Nat. Commun. 11 (1), 1-13

Thimmegowda, G. G., Mullen, S., Sottilare, K., Sharma, A., Mohanta, S. S., Brockmann, A., Dhandapany, P. S., Olsson, S. B. (2020) A field-based quantitative analysis of sublethal effects of air pollution on pollinators. Proc. Natl. Acad. Sci. U. S. A. 117 (34), 2065320661

Underwood, B. A. (1991) Thermoregulation and energetic decision-making by the honeybees Apis cerana, Apis dorsata and Apis laboriosa. J. Exp. Biol. 157 (1), 1934

Visscher, P. K., Seeley, T. D. (1982) Foraging strategy of honeybee colonies in a temperate deciduous forest. Ecology 63 (6), 1790-1801

von Frisch, K. (1967) The dance language and orientation of bees. Cambridge, MA: Harvard University Press

Waddington, K. D., Herbst, L. H. (1987) Body size and the functional length of the proboscis of honey bees. Fla. Entomol. 124-128

Warrant, E. J. (2008) Seeing in the dark: vision and visual behaviour in nocturnal bees and wasps. J. Exp. Biol. 211 (11), 1737-1746

Willmer, P. G., Stone, G. N. (2004) Behavioral, ecological, and physiological determinants of the activity patterns of bees. Adv. Study Behav. 34 (34), 347-466

Publisher's note Springer Nature remains neutral with regard to jurisdictional claims in published maps and institutional affiliations. 